\title{
Application of Nickel Ferrite Nanoparticles in Adsorption of Amoxicillin Antibiotic
}

\author{
Patricia M. A. Caetano, ${ }^{(\infty, a, b, c}$ Nathália M. Simões, ${ }^{a}$ Paula S. Pinto, ${ }^{c, d}$ \\ Luis E. Fernandez-Outon, ${ }^{a, e}$ Adriana S. Albuquerque, ${ }^{a}$ Waldemar A. A. Macedo ${ }^{a}$ \\ and José D. Ardisson ${ }^{a}$
}

${ }^{a}$ Centro de Desenvolvimento da Tecnologia Nuclear (CDTN), Av. Presidente Antônio Carlos, 6627,
31270-901 Belo Horizonte-MG, Brazil

${ }^{b}$ Centro Universitário UNA, Rua dos Aimorés, 1451, 30140-071 Belo Horizonte-MG, Brazil

'Departamento de Química, Universidade do Estado de Minas Gerais (UEMG), 35501-170 Divinópolis-MG, Brazil

${ }^{d}$ Departamento de Química, Universidade Federal de Minas Gerais (UFMG), 31270-901 Belo Horizonte-MG, Brazil

${ }^{e}$ Departamento de Física, Universidade Federal de Minas Gerais (UFMG), 31270-901 Belo Horizonte-MG, Brazil

\begin{abstract}
According to the World Health Organization, amoxicillin (AMX) is the most widely consumed antibiotic in the world. Consequently, there is great interest in the development of new technologies that allow the removal of this type of contaminant, as exposure to antibiotic residues can cause a variety of adverse effects, such as toxicity and antimicrobial resistance. In this work, AMX adsorption from aqueous solution was investigated using nickel ferrite nanoparticles. The nanoadsorbents were prepared by the coprecipitation method, annealed at 300 to $700{ }^{\circ} \mathrm{C}$, and characterized by X-ray diffraction (XRD), transmission electron microscopy (TEM), Mössbauer spectroscopy (ME) and vibratory sample magnetometry (VSM). Nanoparticle size, $\mathrm{pH}$ and temperature were found to significantly affect the amount of adsorbed AMX. The pseudo-second order kinetic model described the adsorption process and the adsorption isotherm fitted to the Freundlich model. AMX adsorption capacity was 104-45 mg g $\mathrm{g}^{-1}$ (miligram of AMX per gram of ferrite) for ferrite annealed at $300-700{ }^{\circ} \mathrm{C}$, respectively. The nanoadsorbents employed showed higher AMX removal efficiency when compared to other iron oxides. Moreover, the good reuse results obtained showed their great potential for antibiotic removal by adsorption.
\end{abstract}

Keywords: ferrite, adsorption, amoxicillin, beta-lactam

\section{Introduction}

Water quality is one of the major environmental concerns today. In particular, the occurrence and destination of drugs to the aquatic environment in recent decades has been recognized as one of the emerging problems of our civilization, since they affect both the Earth's ecosystems, and the health and quality of life of the human beings. ${ }^{1}$ According to World Health Organization report ${ }^{2}$ on surveillance of antibiotic consumption, amoxicillin (AMX) is the most widely used antibiotic in the world. Furthermore, this antibiotic presents significant ecotoxicity, as suggested

*e-mail: patriciamacaetano@gmail.com by several ecological risk studies ${ }^{3,4}$ for the environment, and also creates drug resistance. Consequently, it is of paramount interest the development of new technologies that allow the effective removal of this type of contaminant from aqueous matrices. ${ }^{2,5,6}$

Conventional water treatment systems do not guarantee the removal of a number of micropollutants, especially drugs. Different studies including photocatalysis, ${ }^{7}$ biodegradation, ${ }^{8}$ nanofiltration, ${ }^{9}$ thermal treatment ${ }^{10}$ and adsorption ${ }^{4,6}$ have been applied in drug removal processes. However, of all treatment methods that have been developed, adsorption is the most effective and promising method for removing organic and inorganic micro pollutants, due to their low cost, reproducibility, 
simple operation, and effectiveness. ${ }^{11}$ The choice of adsorbent with exceptional adsorption efficiency is key to the adsorption technique. Carbon nanotubes and activated carbon have been studied to promote amoxicillin adsorption, but there are some limitations on the use of these materials as adsorbent. Adsorption using activated carbon is relatively expensive because activated carbon is hardly regenerated after adsorption, and microporous activated carbon, although efficient, has a limitation in the adsorption process due to the relatively large size of AMX molecules. When evaluating carbon nanotubes, these materials are very hydrophobic and poor interaction with water makes the adsorption process difficult. ${ }^{12-14}$

Among the new generation of adsorbent materials, magnetic nanoadsorbents are the most promising, due to the different properties such as: high surface area, adjustable morphology, and high efficiency, being easily separated from the solution after the adsorption process. ${ }^{15}$

In this context, ferrite nanoparticles have shown interesting properties as adsorbents in the removal of AMX in aqueous solutions. ${ }^{16}$ The most relevant characteristics in the adsorptive capacity of $\mathrm{NiFe}_{2} \mathrm{O}_{4}$ nanoparticles include: increased specific surface area and high adsorption capacity; besides, the ferrite spinel geometry consists of two types of sites, tetrahedral sites (A) and octahedral sites (B), which play a significant role in the control of the adsorption characteristics and magnetic properties. ${ }^{17,18}$ The superparamagnetic behavior allows easy separation from liquids/solids and eventually the regeneration and recycling of magnetic adsorbents. In addition, it is known that iron and other transition metals such as $\mathrm{Co}^{2+}, \mathrm{Co}^{3+}$ and $\mathrm{Ni}^{2+}$ can complex with antibiotic molecules. ${ }^{19}$ Although the publications in the area of environmental remediation are increasing in the last years, by the time of preparation of this article it has not been found any published article specifically related to the capacity of adsorption of amoxicillin by $\mathrm{NiFe}_{2} \mathrm{O}_{4}$ nanoparticles synthesized by coprecipitation method and annealed at different temperatures.

In this work, the adsorption and subsequent removal of AMX from aqueous solution was investigated using $\mathrm{NiFe}_{2} \mathrm{O}_{4}$ nanoparticles annealed at temperatures ranging from 300 to $700{ }^{\circ} \mathrm{C}$. Samples were prepared by the coprecipitation method and characterized by X-ray diffraction (XRD), Mössbauer spectroscopy (MS), transmission electron microscopy (TEM), vibrating sample magnetometry (VSM) and the specific surface area was determined by Brunauer-Emmet-Teller (BET) method based on adsorption/desorption isotherms of nitrogen. The effects of different operational parameters that affect the removal process were investigated: adsorbent amounts, contact time, temperature and surface area.

\section{Experimental}

$\mathrm{NiFe}_{2} \mathrm{O}_{4}$ nanoparticles were prepared by chemical coprecipitation method. Aqueous solution of iron nitrate $\left[\left(\mathrm{Fe}\left(\mathrm{NO}_{3}\right)_{3} .9 \mathrm{H}_{2} \mathrm{O}\right)\right]$ (Dinâmica, São Paulo, SP, Brazil) and nickel nitrate $\left[\left(\mathrm{Ni}\left(\mathrm{NO}_{3}\right)_{2} \cdot 6 \mathrm{H}_{2} \mathrm{O}\right)\right]$ (Dinâmica, São Paulo, SP, Brazil), with stoichiometric ratio $\mathrm{Ni}: \mathrm{Fe}=1: 2$ were stirred for $1 \mathrm{~h}$ (for each $1 \mathrm{~g}$ of nitrate, $3.3 \mathrm{~mL}$ of Milli-Q water (Millipore, Bedford, USA) were used). After this period, the nitrates were added to the $\mathrm{NaOH}$ (Neon, Suzano, SP, Brazil). It was used $3.3 \mathrm{~g}$ of $\mathrm{NaOH}$ diluted in $31.0 \mathrm{~mL}$ for each $1 \mathrm{~g}$ of nitrate, followed by further stirring for $15 \mathrm{~min}$. The resultant materials were annealed at different temperatures in a muffle furnace for a period of $2 \mathrm{~h}$, in ordinary atmosphere..$^{20,21}$ The annealing temperatures used were $300,400,500,600$ and $700{ }^{\circ} \mathrm{C}$ to obtain different particles sizes. The particle size, morphology, specific surface area and magnetic properties of the adsorbent $\mathrm{NiFe}_{2} \mathrm{O}_{4}$ nanoparticles were measured using XRD, TEM, MS and VSM. The specific surface area was determined by BET method based on adsorption/desorption isotherms of nitrogen. The zeta potential has been measured with a Malvern NanoZS HT Zetasizer. The analyses were performed with a concentration of $0.5 \mathrm{mg} \mathrm{mL}^{-1}$ of the samples of ferrites dispersed in Milli-Q water, the $\mathrm{pH}$ variation was performed using $0.5 \mathrm{~mol} \mathrm{~L}^{-1}$ sodium hydroxide (Neon, Suzano, SP, Brazil) and $0.5 \mathrm{~mol} \mathrm{~L}^{-1}$ hydrochloric acid (Neon, Suzano, SP, Brazil).

The adsorption experiments were performed using $20 \mathrm{~mL}$ of AMX solution with a concentration of $200 \mathrm{mg} \mathrm{L}^{-1}$ and $20 \mathrm{mg}$ of ferrite, at $\mathrm{pH}$ 7. The mixture was stirred at $200 \mathrm{rpm}$ for $24 \mathrm{~h}$ at $25^{\circ} \mathrm{C}$, filtered using a $45 \mu \mathrm{m}$ syringe filter, and analyzed on a spectrophotometer (T60 UV-Visible, PG Instruments). The AMX removal was calculated using the adsorption band at $272 \mathrm{~nm}$ (see Figure S1, Supplementary Information (SI) section). ${ }^{13}$ The adsorbed quantity per unit mass of ferrite and the percentages of adsorbates removed were calculated using equations 1 and 2, respectively.

$q=\frac{\left(c_{o}-c_{f}\right) V}{m}$

$\operatorname{Removal}(\%)=\frac{\left(\mathrm{c}_{\mathrm{o}}-\mathrm{c}_{\mathrm{f}}\right)}{\mathrm{c}_{\mathrm{o}}} \times 100$

where, $\mathrm{q}$ is amount of adsorbed AMX per gram of ferrite $\left(\mathrm{mg} \mathrm{g}^{-1}\right), \mathrm{C}_{\mathrm{o}}$ and $\mathrm{C}_{\mathrm{f}}$ are the concentration of AMX at the initial time $(\mathrm{t}=0)$ and after a given time $(\mathrm{t})\left(\mathrm{mg} \mathrm{L}^{-1}\right)$, respectively, $\mathrm{V}$ is the volume of the aqueous phase $(\mathrm{L})$ and $\mathrm{m}$ is the mass of the adsorbent $(\mathrm{g})$. 
The effects of $\mathrm{pH}(2-11)$, contact time (0-2880 min), initial AMX concentration $\left(25-250 \mathrm{mg} \mathrm{L}^{-1}\right)$ and temperature $\left(20-40{ }^{\circ} \mathrm{C}\right)$ of the AMX solution were investigated. Also, kinetics and adsorption isotherms were analyzed. Competitive adsorption experiments were carried out using $200 \mathrm{mg} \mathrm{L}^{-1}$ AMX solutions in the presence of phosphate. The capacity of reuse of $\mathrm{NiFe}_{2} \mathrm{O}_{4}$ in the adsorption of AMX was evaluated. After the first use, the nanoparticles were recovered by magnetic separation. Using a filter to retain the adsorbent, nanoparticles were washed with Milli-Q water to remove the AMX adsorbed on their surface and then dried. Subsequently, the material was used again under the same experimental conditions mentioned previously.

\section{Results and Discussion}

XRD spectra of $\mathrm{NiFe}_{2} \mathrm{O}_{4}$ samples annealed at 300, 400, 500, 600 and $700{ }^{\circ} \mathrm{C}$ are shown in Figure 1. All the reflection planes observed in the diffractograms confirmed the formation of the cubic spinel structure of nickel ferrite (reference data of Joint Committee on Powder Diffraction Standards, JCPDS card No. 742081). A significant increase in intensity and reduction of the width of the diffraction peaks was observed, indicating an increase in crystallinity and particle diameter with increasing annealing temperature. These results agree with published data ${ }^{22}$ for $\mathrm{Co}$ and $\mathrm{Ni}$ ferrite

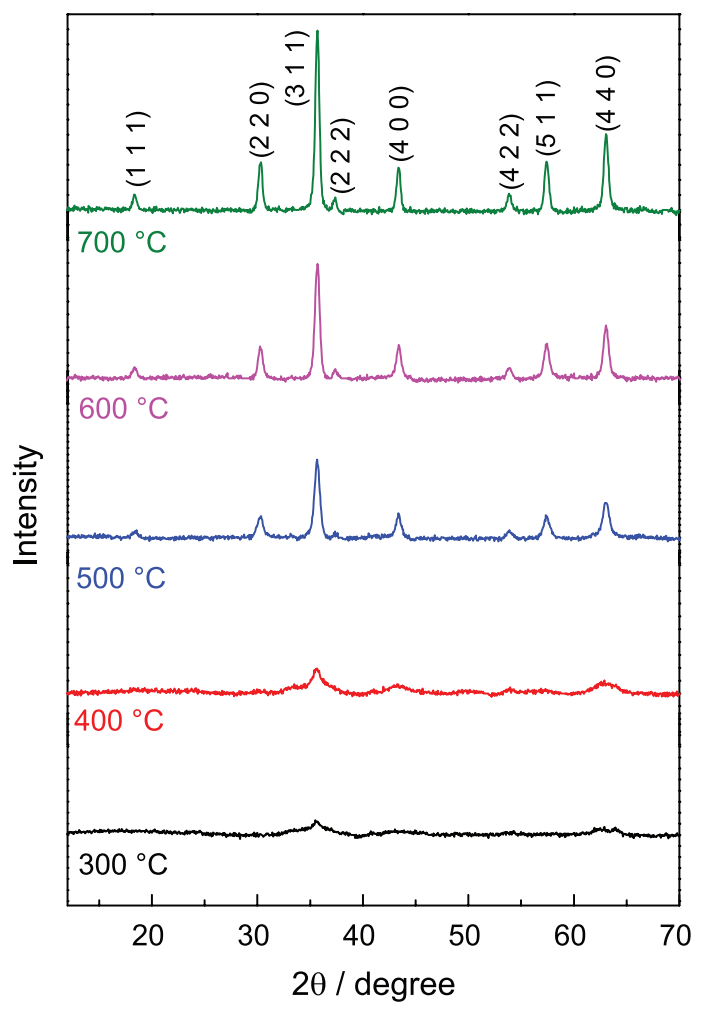

Figure 1. XRD patterns of $\mathrm{NiFe}_{2} \mathrm{O}_{4}$ nanoparticles annealed at different temperatures.
Table 1. Average particle size, specific area and pore volume of $\mathrm{NiFe}_{2} \mathrm{O}_{4}$ samples

\begin{tabular}{lccc}
\hline $\begin{array}{l}\text { Annealing } \\
\text { temperature } /{ }^{\circ} \mathrm{C}\end{array}$ & $\begin{array}{c}\text { Mean crystallite } \\
\text { size / } \mathrm{nm}\end{array}$ & $\begin{array}{c}\text { Specific surface } \\
\text { area } /\left(\mathrm{m}^{2} \mathrm{~g}^{-1}\right)\end{array}$ & $\begin{array}{c}\text { Total pore } \\
\text { volume / } \\
\left(\mathrm{cm}^{3} \mathrm{~g}^{-1}\right)\end{array}$ \\
\hline 300 & $4 \pm 2$ & 212 & 0.23 \\
400 & $6 \pm 2$ & 147 & 0.25 \\
500 & $16 \pm 2$ & 53 & 0.20 \\
600 & $20 \pm 2$ & 31 & 0.16 \\
\hline
\end{tabular}

nanoparticles. The mean particle diameter estimated by the Scherrer equation ranged from 3 to $25 \mathrm{~nm}$ (Table 1).

The shape, size and morphology of the single-phase particles were examined by direct observation (TEM). The TEM micrographs corresponding to the sample annealed at $400{ }^{\circ} \mathrm{C}$, shown in Figure 2, reveal that the particles are approximately spherical, with median diameter of $10 \mathrm{~nm}$ and standard deviation of $3 \mathrm{~nm}$.

The surface area of the ferrites was measured using nitrogen adsorption/desorption isotherms at $77 \mathrm{~K}$ by the BET method (Table 1). Samples annealed at $300{ }^{\circ} \mathrm{C}$ have higher surface area compared to the other samples. This result was already expected since the increase of the annealing temperature favors particle growth, as verified by XRD, and consequently the surface area is reduced. The values obtained are similar to those found in the literature. ${ }^{23,24}$

Figure $3 \mathrm{a}$ shows the adsorption and desorption isotherms of $\mathrm{N}_{2}$, in addition to the pore diameter distribution curve. The samples showed isothermal profiles characteristic of mesoporous materials (type IV according to the International Union of Pure and Applied Chemistry, IUPAC, classification). ${ }^{25}$ The pore diameter distribution profiles, shown in Figure 3b, exhibit a narrow range of pore distribution, in which the majority of the pore diameter is located in the 2 to $20 \mathrm{~nm}$ range, characteristic of mesoporous materials. ${ }^{25}$

Mössbauer spectra were measured at 25 and at $-248.5^{\circ} \mathrm{C}$ (Figure 4). The spectra were fitted using sextets, associated to $\mathrm{Fe}^{3+}$ in tetrahedral (A) and octahedral (B) sites. Samples annealed at 300 and $400{ }^{\circ} \mathrm{C}$ exhibit collapsed hyperfine fields at (A) and (B) sites, suggesting superparamagnetic behavior at room temperature. Spectra for samples annealed at 500, 600 and $700{ }^{\circ} \mathrm{C}$ exhibit narrower lines, due to an increased degree of crystallinity. ${ }^{26}$ The hyperfine parameters obtained from the fitting of the spectra are shown in Table 2.

The $\mathrm{M}-\mathrm{H}$ hysteresis loops were measured using a vibrating sample magnetometer (Figure 5). It is observed that the saturation magnetization $\left(\mathrm{M}_{\mathrm{S}}\right)$ increases with 


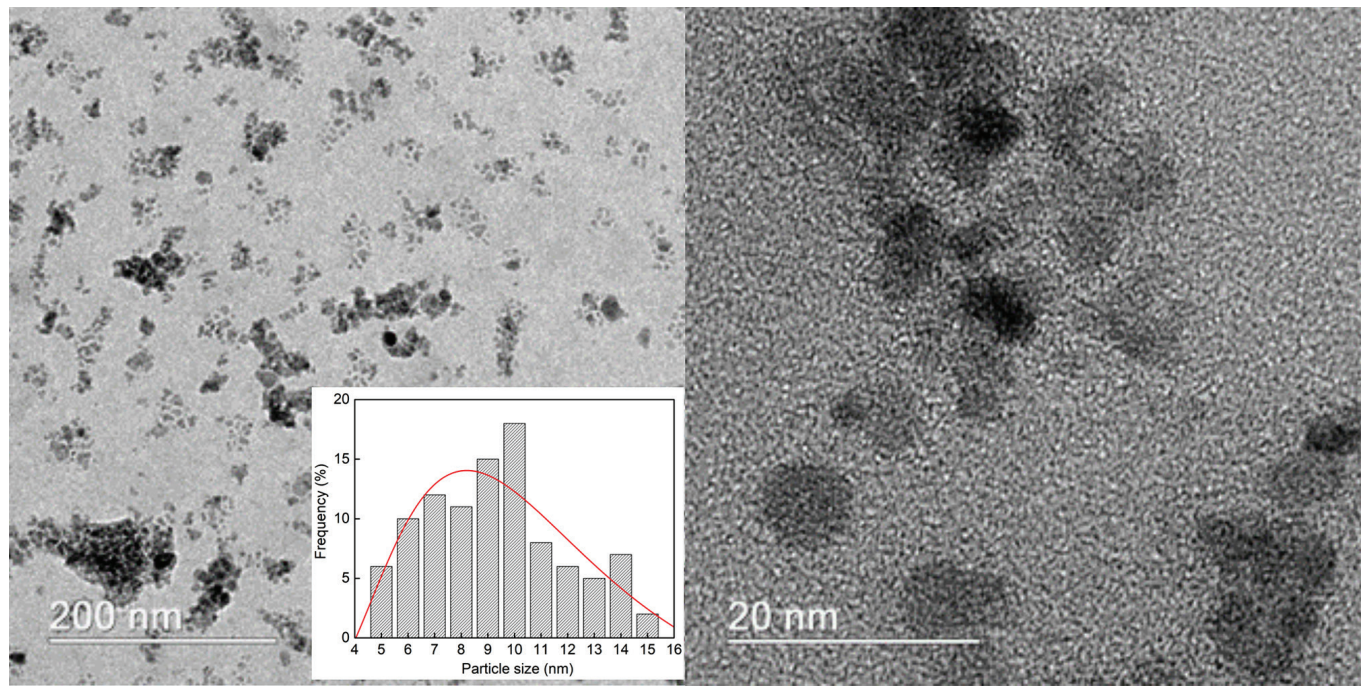

Figure 2. TEM images of $\mathrm{NiFe}_{2} \mathrm{O}_{4}$ annealed at $400{ }^{\circ} \mathrm{C}$.
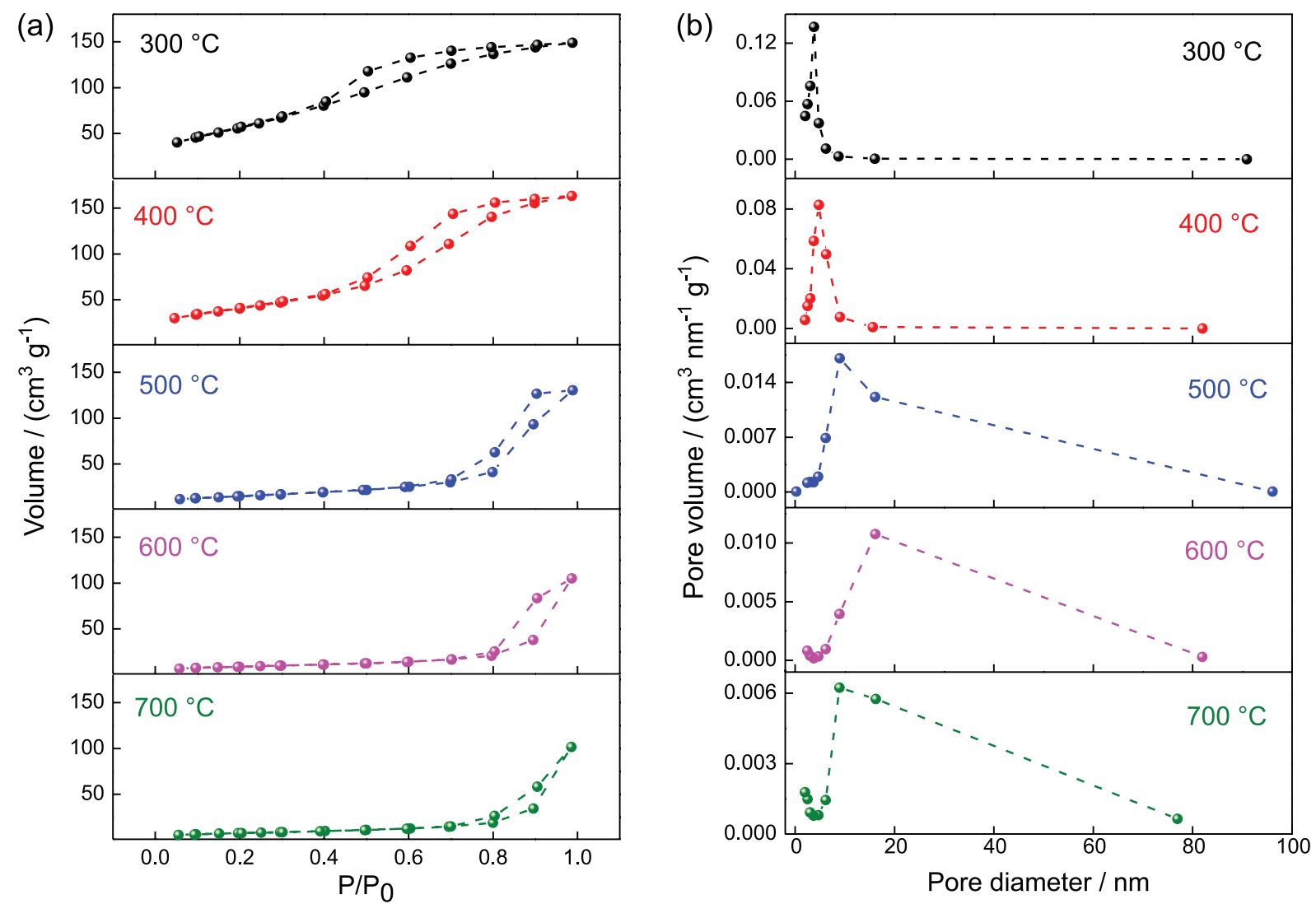

Figure 3. (a) $\mathrm{N}_{2}$ adsorption-desorption isotherms and (b) pore size distribution curves of $\mathrm{NiFe}_{2} \mathrm{O}_{4}$ annealed at $300,400,500,600$ and $700{ }^{\circ} \mathrm{C}$.

annealing temperature, as consequence of the particle size increase, which involves the reduction of surface to volume spins, and consequently resulting in the enhancement of saturation magnetization. Table 2 shows the variation of coercivity $\left(\mathrm{H}_{\mathrm{C}}\right)$ with annealing temperature, being largest for the nanoparticles annealed at $600{ }^{\circ} \mathrm{C}$, having mean diameter of $20 \mathrm{~nm}$. It is well known that $\mathrm{H}_{\mathrm{C}}$ is very sensitive to the particle size distribution. It is observed that up to $600{ }^{\circ} \mathrm{C}$ both particle size and coercivity increase. However, for annealing temperatures above $600{ }^{\circ} \mathrm{C}$, the coercivity decreases, even though the particle size is still larger. ${ }^{27}$ This fact should be related to a transition from monodomain to multidomain around these values of the particle diameter or a change in the magnetization reversal mode..$^{28}$ 

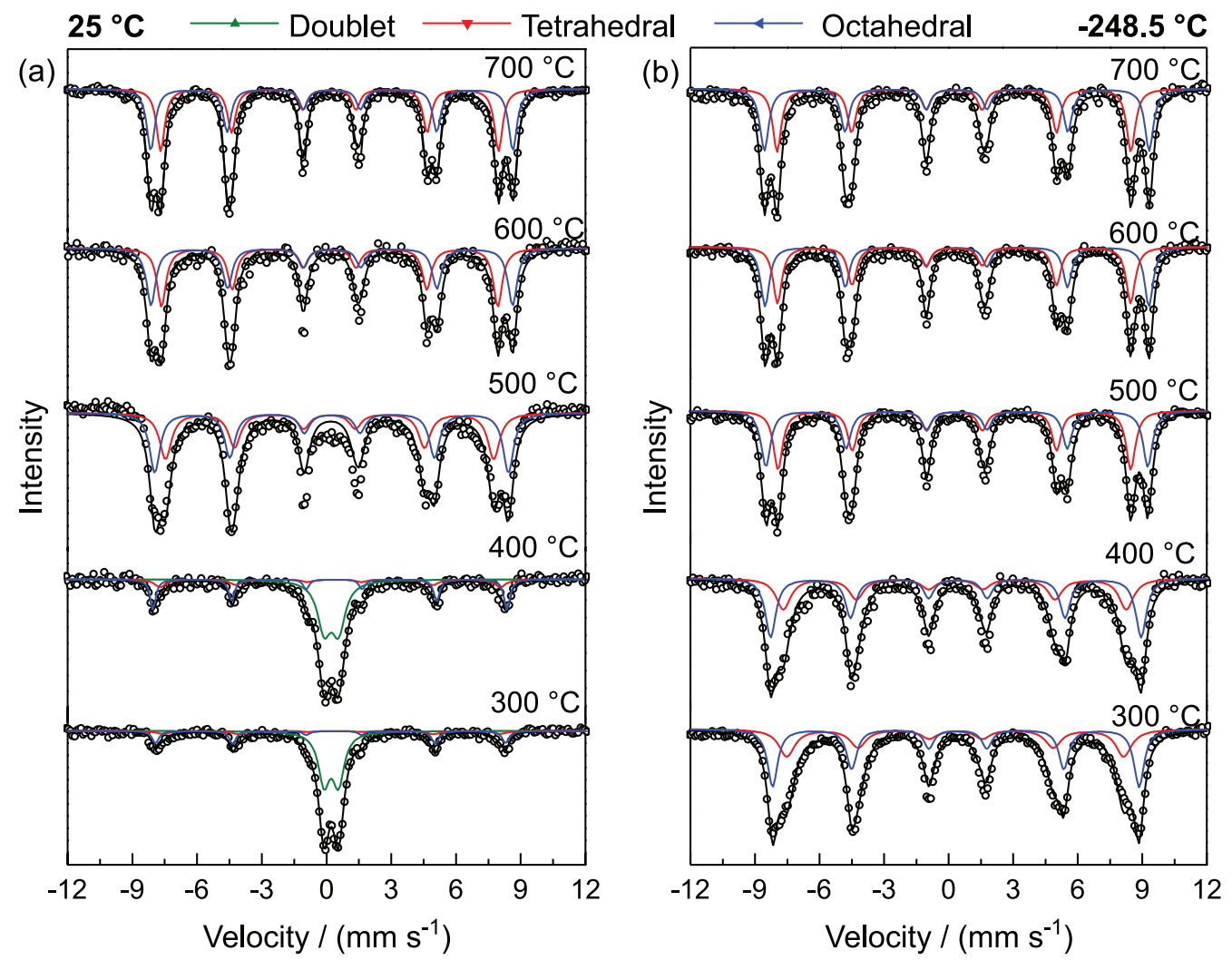

Figure 4. Mössbauer spectra for $\mathrm{NiFe}_{2} \mathrm{O}_{4}$ annealed at different temperatures measured at (a) 25 and (b) $-248.5{ }^{\circ} \mathrm{C}$.

Table 2. Hyperfine parameters, saturation magnetization and coercivity of $\mathrm{NiFe}_{2} \mathrm{O}_{4}$ samples

\begin{tabular}{|c|c|c|c|c|c|c|c|c|c|c|c|}
\hline \multirow{3}{*}{$\mathrm{T} /{ }^{\circ} \mathrm{C}$} & \multirow{3}{*}{ Site } & $\delta \pm 0$. & $\left.\mathrm{mm} \mathrm{s}^{-1}\right)$ & \multicolumn{2}{|c|}{$\varepsilon \pm 0.05 /\left(\mathrm{mm} \mathrm{s}^{-1}\right)$} & \multicolumn{2}{|c|}{$\mathrm{B}_{\mathrm{HF}} \pm 0.5 / \mathrm{T}$} & \multicolumn{2}{|c|}{$\mathrm{RA} \pm 1 / \%$} & \multirow{3}{*}{$\begin{array}{c}\mathrm{M}_{\mathrm{S}} \pm 3 / \\
\left(\mathrm{emu} \mathrm{g}^{-1}\right)\end{array}$} & \multirow{3}{*}{$\begin{array}{c}\mathrm{H}_{\mathrm{C}} \pm 3 / \\
\mathrm{Oe}\end{array}$} \\
\hline & & \multicolumn{8}{|c|}{ Mössbauer spectroscopy measurement temperature $/{ }^{\circ} \mathrm{C}$} & & \\
\hline & & 25 & -248.5 & 25 & -248.5 & 25 & -248.5 & 25 & -248.5 & & \\
\hline \multirow{3}{*}{300} & sextet $\mathrm{A}$ & 0.32 & 0.32 & -0.19 & -0.02 & 48 & 48 & 9 & 37 & \multirow{3}{*}{8} & \multirow{3}{*}{11} \\
\hline & sextet $B$ & 0.33 & 0.38 & -0.15 & -0.09 & 50 & 52 & 21 & 63 & & \\
\hline & doublet & 0.22 & & 0.67 & & - & & 70 & & & \\
\hline \multirow{3}{*}{400} & sextet A & 0.25 & 0.31 & -0.19 & -0.03 & 48 & 49 & 8 & 40 & \multirow{3}{*}{9} & \multirow{3}{*}{19} \\
\hline & sextet B & 0.27 & 0.38 & -0.20 & -0.09 & 50 & 53 & 27 & 60 & & \\
\hline & doublet & 0.22 & & 0.66 & & - & & 65 & & & \\
\hline \multirow{2}{*}{500} & sextet A & 0.14 & 0.27 & 0.01 & -0.01 & 47 & 50 & 42 & 46 & \multirow{2}{*}{32} & \multirow{2}{*}{45} \\
\hline & sextet B & 0.25 & 0.38 & -0.03 & 0.00 & 50 & 55 & 58 & 54 & & \\
\hline \multirow{2}{*}{600} & sextet A & 0.14 & 0.26 & 0.01 & -0.01 & 48 & 50 & 47 & 48 & \multirow{2}{*}{36} & \multirow{2}{*}{110} \\
\hline & sextet B & 0.25 & 0.37 & -0.02 & 0.02 & 51 & 55 & 53 & 52 & & \\
\hline \multirow{2}{*}{700} & sextet $\mathrm{A}$ & 0.14 & 0.25 & 0.01 & -0.01 & 48 & 51 & 48 & 49 & \multirow{2}{*}{39} & \multirow{2}{*}{45} \\
\hline & sextet B & 0.25 & 0.37 & -0.01 & -0.02 & 52 & 55 & 52 & 51 & & \\
\hline
\end{tabular}

T: annealing temperature; $\delta$ : isomer shift relative to $\alpha$-Fe at room temperature; $\varepsilon$ : quadrupole splitting; $\mathrm{B}_{\mathrm{HF}}$ : hyperfine field; RA: relative spectral areas; $\mathrm{M}_{\mathrm{S}}$ : saturation magnetization; $\mathrm{H}_{\mathrm{C}}$ : coercivity.

Nanoparticles of nickel ferrite annealed at 300, 400, 500,600 and $700{ }^{\circ} \mathrm{C}$ were subjected to AMX adsorption experiments, and the results are shown in Figure 6a. It was observed that increasing the annealing temperature caused a reduction in the adsorption capacity of the samples, as expected, since the adsorption is a surface phenomenon, and, therefore, materials with greater surface area have greater capacity of adsorption. ${ }^{29}$

High surface area and especially mesoporosity are important for the entry of the relatively large molecules 


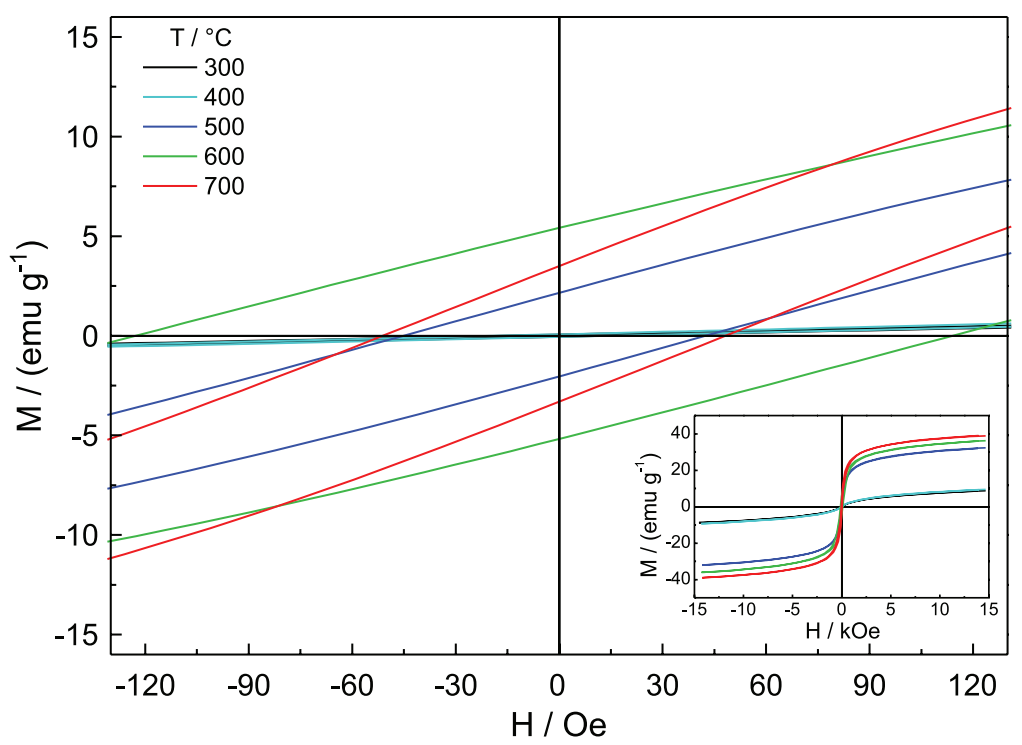

Figure 5. Hysteresis loops of $\mathrm{NiFe}_{2} \mathrm{O}_{4}$ annealed at different temperatures.
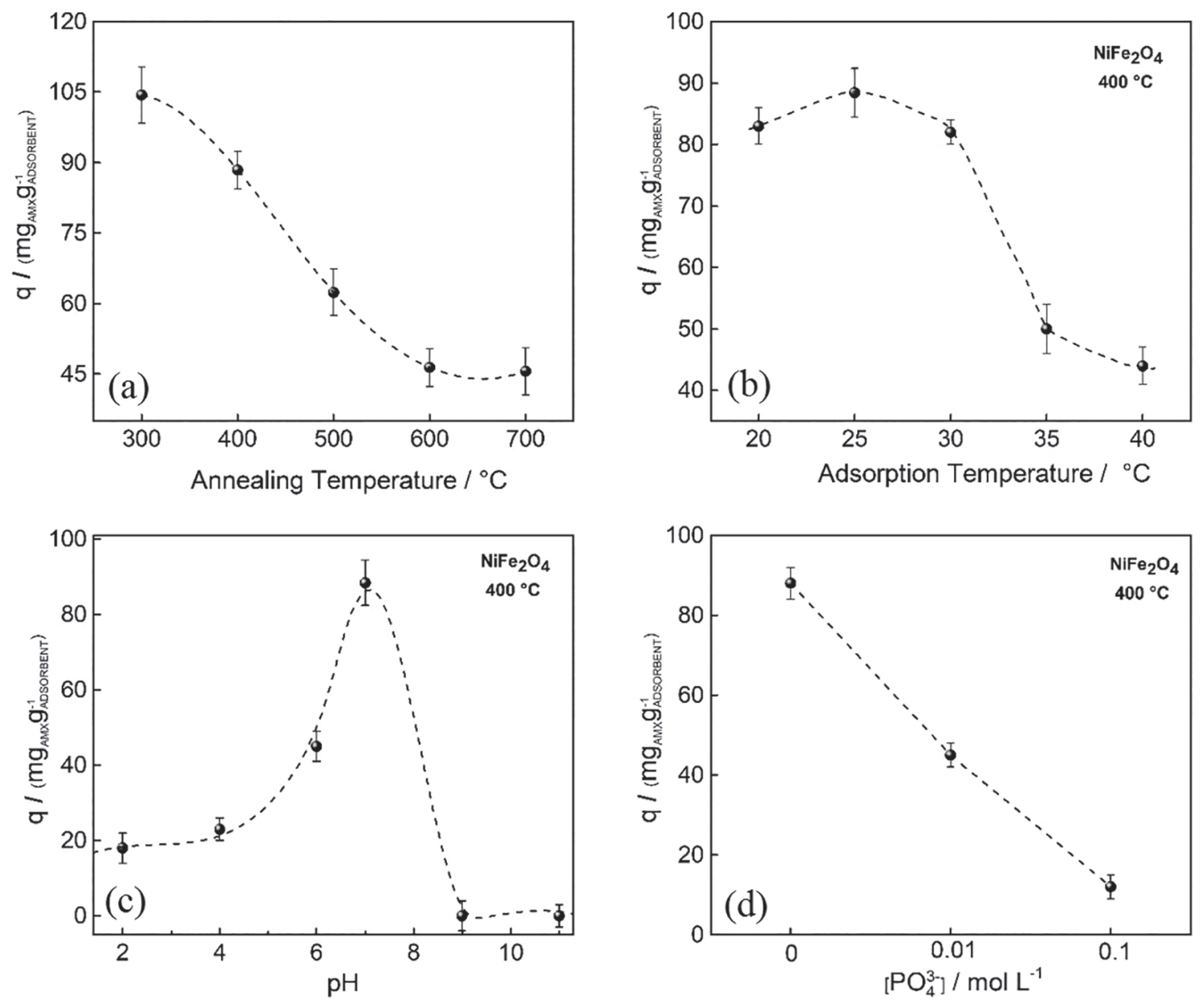

Figure 6. (a) Adsorptive capacity in the removal of amoxicillin from nickel ferrite nanoparticles annealed at different temperatures per gram of ferrite; effect of (b) temperature, (c) $\mathrm{pH}$ on the adsorption process of amoxicillin and (d) amoxicillin adsorption in the presence of phosphate.

of antibiotics to interact with the specific sites on the surface of the adsorbent. ${ }^{13}$ However, despite the surface area is important for increased adsorption rates, there are other factors playing a major role in the adsorption process. Previous works ${ }^{5,13,30-32}$ indicate that iron and nickel species can interact with beta-lactam antibiotics through a 
complexation, forming stable intermediates and allowing increased adsorption of AMX. Those transition metals show variable oxidation states according to the catalyst, reacting element or compound, and the conditions of the reaction in which they are involved. Thus, they can form a large number of complex compounds. ${ }^{33}$

The $\mathrm{NiFe}_{2} \mathrm{O}_{4}$ ferrite at $400{ }^{\circ} \mathrm{C}$ was chosen as the model for more specific tests, such as temperature and $\mathrm{pH}$, influence on adsorption, equilibrium isotherms and adsorption kinetics. Although this sample did not present the best adsorptive capacity compared to the annealed sample at $300{ }^{\circ} \mathrm{C}$, it was selected because of its better crystallinity and its more pronounced magnetic properties, facilitating its removal in dispersion.

The effect of the solution temperature on the adsorption process was studied between 20 and $40{ }^{\circ} \mathrm{C}$, using $\mathrm{NiFe}_{2} \mathrm{O}_{4}$ annealed at $400{ }^{\circ} \mathrm{C}$. The results obtained are shown in Figure $6 \mathrm{~b}$. It can be observed that between 20 and $30^{\circ} \mathrm{C}$, the temperature does not significantly influence the adsorption process. However, at 35 and $40^{\circ} \mathrm{C}$ there is a marked decrease on the adsorption rate. Equilibrium and kinetic studies of adsorption in aqueous solution indicate that this effect may be related to the weakening of the ligand forces between the active sites of the adsorbent and the adsorbate molecules. ${ }^{34}$

The $\mathrm{pH}$ is one of the most important factors that could affect the adsorption process of organic materials, since the solubility of adsorbate and electric charge of the active sites on material surface can change depending on the $\mathrm{pH}$ value. ${ }^{35,36}$ In order to evaluate the $\mathrm{pH}$ effect of the solution in the adsorption process, experiments varying the $\mathrm{pH}$ from 2 to 11 were performed (Figure 6c). The amount of amoxicillin adsorbed increased in the range of $\mathrm{pH} 2$ to 7 and the best result for amoxicillin removal was at $\mathrm{pH} 7$, corresponding to $87 \mathrm{mg}_{\text {AMX }} \mathrm{g}_{\text {ADSORBENT }}{ }^{-1}$.

Amoxicillin is an amphoteric compound, thus presents more than one dissociation constants. The relationship between the $\mathrm{pH}$ effect of the solution and the adsorption of amoxicillin by the ferrite nanoparticles can be explained by considering the surface charge of the adsorbent and the dissociation constant $\left(\mathrm{p} K_{\mathrm{a}}\right) \cdot{ }^{37,38} \mathrm{At}$ this point, it is interesting to consider that nickel ferrites annealed at $400{ }^{\circ} \mathrm{C}$ have point of zero charge (PZC) around 7.7 (see Figure S2, SI section) meaning that its surface is positively charged. AMX has three dissociation constants $\left(\mathrm{p} K_{\mathrm{a} 1}=2.68, \mathrm{p} K_{\mathrm{a} 2}=7.49\right.$ and $\left.\mathrm{p} K_{\mathrm{a} 3}=9.63\right)$ and is mainly in the zwitterion form at $\mathrm{pH}$ values between 3 and 7 . There is a $\beta$-lactam ring in its structure, making it susceptible to degradation by acid or basic hydrolysis. ${ }^{39}$ Therefore, it is expected that in extreme $\mathrm{pH}$ values the degradation of AMX will occur.

Besides the adsorptive capacity, the leaching of the metals is another factor that depends on the $\mathrm{pH}$ value, and in more acidic pHs there is an increase of the solubility of the metal in solution. ${ }^{40}$ Atomic absorption measurements in the aqueous phase showed no significant $\mathrm{Fe}^{3+}$ leaching from the material. The highest values found were in $\mathrm{pH} 2$ and 4 , of 1.3 and $0.2 \mathrm{ppm}$ of $\mathrm{Fe}^{3+}$, respectively.

The study of the equilibrium adsorption is of great importance for the understanding of the mechanisms that govern the interactions of a molecule with a solid sorbent. ${ }^{41}$ For this purpose, the Langmuir and Freundlich isotherm models were used to fit the experimental data..$^{42}$ The results are summarized in Table 3 and Figure 7a.

Table 3. Parameters of the Langmuir and Freundlich isotherms

\begin{tabular}{lccc}
\hline & \multicolumn{2}{c}{ Langmuir } & \multicolumn{2}{c}{ Freundlich } \\
\hline $\mathrm{q} /\left(\mathrm{mg} \mathrm{g}^{-1}\right)$ & $97.654 \pm 0.040$ & $\mathrm{~K}$ & $1.177 \pm 0.090$ \\
$\mathrm{~b}$ & $0.054 \pm 0.080$ & $\mathrm{n}$ & $1.393 \pm 0.021$ \\
$\mathrm{R}^{2}$ & 0.446 & $\mathrm{R}^{2}$ & 0.993 \\
\hline
\end{tabular}

q: amount of solute adsorbed per gram of adsorbent; b: constant equilibrium; K: experimental constant, which indicates the adsorption capacity of the adsorbent; $n$ : experimental constant, which indicates the effect of concentration on adsorption capacity; $\mathrm{R}^{2}$ : coefficient of determination.

Experimental data were best fitted by a Freundlich isotherm, using equation 3 , where $\mathrm{K}_{\mathrm{F}}$ and $\mathrm{n}$ are the Freundlich constants associated to relative capacity and to the adsorption intensity, respectively, $\mathrm{C}_{\mathrm{e}}$ is the equilibrium concentration, and $\mathrm{q}_{\mathrm{e}}$ is the amount of adsorbate adsorbed.

$\log \mathrm{q}_{\mathrm{e}}=\ln \mathrm{K}_{\mathrm{F}}+\frac{1}{\mathrm{n}} \log \mathrm{C}_{\mathrm{e}}$

These results indicate that the adsorbent material is expected to have a heterogeneous surface, where the adsorption occurs in multilayers, having active sites with different energies. ${ }^{43,44}$

Figure $7 \mathrm{~b}$ shows the contact time required to reach equilibrium of AMX adsorption. It is observed that initially the adsorption process is very fast, decreasing gradually until equilibrium is reached, after $10 \mathrm{~h}$. The adsorption kinetics of AMX was studied using pseudo-first and pseudo-second order models. ${ }^{45}$ The calculated values of $\mathrm{K}$ (experimental constant) and $\mathrm{q}_{\mathrm{e}}$ are shown in Table 4 . Comparison of the coefficient of determination $\left(\mathrm{R}^{2}\right)$ values obtained from the fittings indicates that the secondorder model was the best suited to the experimental data (Figure 7b). The pseudo-second order kinetic model may be represented as:

$\frac{1}{q_{t}}=\frac{1}{K_{2} q_{e}^{2}}+\frac{t}{q_{e}}$ 

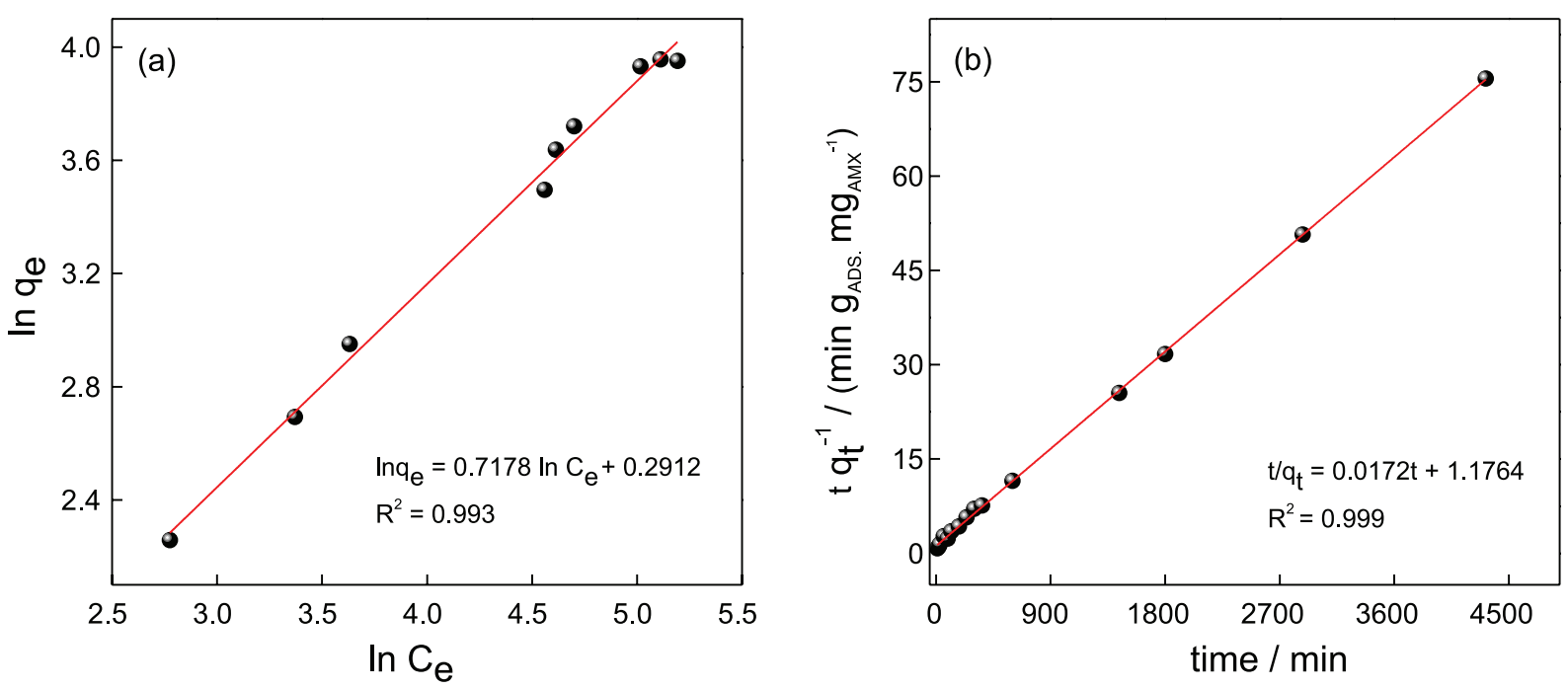

Figure 7. Linearization of (a) adsorption isotherm using the Freundlich model and (b) kinetic curve using the pseudo-second order model.

where $\mathrm{K}_{2}$ is the second-order rate constant and $\mathrm{q}_{\mathrm{t}}$ is the adsorption capacity of the adsorbent at time t. The values of $t / \mathrm{q}_{\mathrm{t}}$ are plotted against $\mathrm{t}, \mathrm{q}_{\mathrm{e}}$ and $\mathrm{K}_{2}$ are calculated from the slope and intercept of the plot. The second-order model considers the adsorption process as a chemical reaction, chemisorption. ${ }^{46}$ Thus, it can be said that the rate of AMX adsorption by $\mathrm{NiFe}_{2} \mathrm{O}_{4}$ nanoparticles is controlled by chemisorption routes, which would involve ion exchange by means of valence forces through the exchange or share of electrons between adsorbate and adsorbent. ${ }^{45}$

Table 4. Parameters of the kinetic models of pseudo-first and pseudosecond order

\begin{tabular}{lccc}
\hline \multicolumn{2}{c}{ Pseudo-first order } & \multicolumn{2}{c}{ Pseudo-second order } \\
\hline $\mathrm{q}_{\mathrm{e}} /\left(\mathrm{mg} \mathrm{g}^{-1}\right)$ & $15.31 \pm 0.01$ & $\mathrm{q}_{\mathrm{e}} /\left(\mathrm{mg} \mathrm{g}^{-1}\right)$ & $69.20 \pm 0.01$ \\
$\mathrm{~K}_{1} /\left(\mathrm{g} \mathrm{mg}^{-1} \mathrm{~min}^{-1}\right)$ & $0.50 \pm 0.01$ & $\mathrm{~K}_{2} /\left(\mathrm{g} \mathrm{mg}^{-1} \mathrm{~min}^{-1}\right)$ & $0.85 \pm 0.01$ \\
$\mathrm{R}^{2}$ & 0.729 & $\mathrm{R}^{2}$ & 0.999 \\
\hline
\end{tabular}

$\mathrm{q}_{\mathrm{e}}$ : amount adsorbed at equilibrium time; $\mathrm{K}_{1}$ and $\mathrm{K}_{2}$ : experimental constants; $\mathrm{R}^{2}$ : coefficient of determination.

Aiming to understand the adsorption mechanisms, mainly related to the interaction of iron with the AMX molecule, a competitive adsorption experiment was carried out using phosphates. There is an expressive interaction of the phosphate anions with iron oxides, so the presence of phosphate competes with the complexation of other organic binders. ${ }^{47,48}$ Experiments were performed varying the phosphate concentration to evaluate the effect on the AMX adsorption (Figure 6d).

In absence of phosphate the adsorption of AMX was $88 \mathrm{mg} \mathrm{g}^{-1}$ and in presence of phosphate anions, adsorption capacity decreased to $12 \mathrm{mg} \mathrm{g}^{-1}$ at the same concentration (200 $\mathrm{mg} \mathrm{L}^{-1}$ ) of AMX. This sharp decrease in adsorption capacity with increasing phosphate concentration provides evidence of the remarkable affinity of iron for this anion. Therefore, the strong affinity of phosphates to bind to iron species hampers the interaction between AMX and the $\mathrm{Fe}^{3+}$ species present on the surface of the $\mathrm{NiFe}_{2} \mathrm{O}_{4}$ particles, diminishing significantly the complexation with AMX.

Currently, as far as the authors are aware, there are no published reports on the use of $\mathrm{NiFe}_{2} \mathrm{O}_{4}$ nanoparticles for AMX adsorption, that could be used to compare with the results presented on this article. However, the use of iron oxides in the adsorption of AMX has been reported in several papers. ${ }^{4,6,8,13,49-53} \mathrm{The}_{\mathrm{NiFe}} \mathrm{O}_{4}$ nanoparticles studied presented excellent AMX adsorption results, exhibiting removal rates of $60 \%$ higher when compared to composites containing $\mathrm{Fe}$ oxyhydroxy supported in $\mathrm{Al}_{2} \mathrm{O}_{3} \cdot{ }^{13}$ This favorable ferrite performance indicates that in addition to the specific interaction of the AMX molecule with Fe, Ni should also play an important role in the adsorption of AMX. It is interesting to relate the AMX adsorption capacity of different adsorbents with their respective surface areas.

Table 5 presents some materials used in the adsorption of AMX, along with their surface areas per gram, and the amount of AMX adsorbed per surface area of the adsorbent.

In view of the results obtained, it is possible to note that $\mathrm{NiFe}_{2} \mathrm{O}_{4}$ annealed at $400{ }^{\circ} \mathrm{C}$ showed significantly higher adsorption capacity per surface area when compared with other materials reported in the literature. A possible explanation is that the main interaction of adsorbents based on activated carbon with AMX may be of van der Waals type $^{54,55}$ whilst for composites such as Fe oxyhydroxy supported in $\mathrm{Al}_{2} \mathrm{O}_{3}$ and $\mathrm{NiFe}_{2} \mathrm{O}_{4}$, the adsorption process is suggested to be mediated by a different interaction, being more efficient to complex AMX molecules with the 
Table 5. Comparison of the adsorptive capacity of different adsorbents

\begin{tabular}{|c|c|c|c|}
\hline Adsorbent & Surface area / $\left(\mathrm{m}^{2} \mathrm{~g}^{-1}\right)$ & AMX adsorption / $\left(\mathrm{mg} \mathrm{m}^{-2}\right)$ & Reference \\
\hline Magnetically modified graphene nanoplatelets & 543 & 0.030 & 49 \\
\hline Magnetic adsorbent prepared from olive kernel & 2188 & 0.109 & 6 \\
\hline Mn-impregnated activated carbons & 1033 & 0.121 & 53 \\
\hline Magnetic activated carbon with $\mathrm{Fe}_{3} \mathrm{O}_{4}$ & 671 & 0.210 & 50 \\
\hline $\mathrm{NaOH}$-activated carbon & 2573 & 0.223 & 51 \\
\hline Nanoporous carbon CMK-3 type & 770 & 0.280 & 52 \\
\hline Composites with $\mathrm{Fe}$ oxyhydroxy supported in $\mathrm{Al}_{2} \mathrm{O}_{3}$ & 107 & 0.330 & 16 \\
\hline Nickel ferrite annealed at $300,400,500,600$ and $700{ }^{\circ} \mathrm{C}$, respectively & $\begin{array}{c}212,147,53,31 \\
\text { and } 27\end{array}$ & $\begin{array}{c}0.449,0.600,1.170 \\
1.500 \text { and } 1.670\end{array}$ & this study \\
\hline
\end{tabular}

AMX: amoxicillin.

surface $\mathrm{Fe}^{3+}$ species, and also with $\mathrm{Ni}^{2+}$ species in the case of $\mathrm{NiFe}_{2} \mathrm{O}_{4}$, responsible for the higher adsorption capacity measured.

The capacity of reuse of $\mathrm{NiFe}_{2} \mathrm{O}_{4}$ in the adsorption of AMX was evaluated: in the first cycle of the experiment, the adsorbent material removed $68 \%$ of AMX, in the second cycle $59 \%$ of AMX was removed, $47 \%$ in a third cycle, and $17 \%$ removal was achieved in the fourth adsorption cycle. This satisfactory result implies a significant cost reduction in the process of using $\mathrm{NiFe}_{2} \mathrm{O}_{4}$ nanoparticles as adsorbent agent of AMX in aqueous solution.

\section{Conclusions}

$\mathrm{NiFe}_{2} \mathrm{O}_{4}$ nanoparticles were produced using the coprecipitation method, followed by thermal annealing between 300 and $700{ }^{\circ} \mathrm{C}$, with average size between 4 and $25 \mathrm{~nm}$. The adsorption capacity of $\mathrm{NiFe}_{2} \mathrm{O}_{4}$ nanoparticles to remove amoxicillin from an aqueous solution was found to depend significantly on the nanoparticle average size, the temperature, and the $\mathrm{pH}$ value of the solution. The adsorption process was described by a second order kinetic model and the adsorption isotherm was fitted to the Freundlich model. The amoxicillin adsorption capacity was $104,88,62,46,45 \mathrm{mg} \mathrm{g}^{-1}$ for ferrite annealed at 300, 400, 500,600 and $700{ }^{\circ} \mathrm{C}$, respectively. The nanoadsorbents employed in this work showed higher amoxicillin removal efficiency than that exhibited by other iron oxides. The good reuse results obtained demonstrate that nickel ferrite nanoparticles have great potential in the removal of antibiotics by adsorption.

\section{Supplementary Information}

Supplementary data are available free of charge at http://jbcs.sbq.org.br as PDF file.

\section{Acknowledgments}

This work was supported by CNPq, CAPES, FAPEMIG and CNEN.

\section{Author Contributions}

Patricia M. A. Caetano was responsible for the conceptualization, data curation, investigation, resources, writing original draft, review and editing; Nathália M. Simões for the investigation and data curation; Paula S. Pinto for the conceptualization, methodology and resources; Luis E. Fernandez-Outon for the writing review and editing and visualization; Adriana S. Albuquerque for the conceptualization, project administration, resources, visualization, writing review and editing; Waldemar A. A. Macedo for the resources and visualization; José D. Ardisson for the conceptualization, data curation, formal analysis funding acquisition, project administration, resources, writing review and editing.

\section{References}

1. Kümmerer, K.; Chemosphere 2009, 75, 435.

2. World Health Organization (WHO); WHO Report on Surveillance of Antibiotic Consumption: 2016-2018 Early Implementation; WHO: Geneva, 2018. Available at http:// www.who.int/medicines/areas/rational_use/oms-amr-amcreport-2016-2018/en/, accessed in June 2020.

3. Chem, E. D.; Anong, D. N.; Akoachere, J. F. K. T.; PLoS One 2018, 13, e0193353.

4. Hu, D.; Wang, L.; J. Taiwan Inst. Chem. Eng. 2016, 64, 227.

5. Ghauch, A.; Tuqan, A.; Assi, H. A.; Environ. Pollut. 2009, 157, 1626.

6. Jafari, K.; Heidari, M.; Rahmanian, O.; Ultrason. Sonochem. 2018, 45, 248. 
7. Mirzaei, A.; Chen, Z.; Haghighat, F.; Yerushalmi, L.; Chemosphere 2017, 174, 665.

8. Dong, H.; Yuan, X.; Wang, W.; Qiang, Z.; J. Environ. Manage. 2016, 178, 11.

9. Koyuncu, I.; Arikan, O. A.; Wiesner, M. R.; Rice, C.; J. Memb. Sci. 2008, 309, 94.

10. Roca, M.; Villegas, L.; Kortabitarte, M. L.; Althaus, R. L.; Molina, M. P.; J. Dairy Sci. 2011, 94, 1155.

11. Zhou, J.; Wang, Y.; Wang, J.; Qiao, W.; Long, D.; Ling, L.; J. Colloid Interface Sci. 2016, 462, 200.

12. Purceno, A. D.; Teixeira, A. P. C.; de Souza, N. J.; FernandezOuton, L. E.; Ardisson, J. D.; Lago, R. M.; J. Colloid Interface Sci. 2012, 379, 84.

13. Pinto, P. S.; Medeiros, T. P. V.; Ardisson, J. D.; Lago, R. M.; J. Hazard. Mater. 2016, 317, 327.

14. Chayid, M. A.; Ahmed, M. J.; J. Environ. Chem. Eng. 2015, 3, 1592.

15. Gómez-Pastora, J.; Bringas, E.; Ortiz, I.; Chem. Eng. J. 2014, 256, 187.

16. Ridley, M. K.; Machesky, M. L.; Kubicki, J. D.; Langmuir 2015 , 31, 703.

17. Busch, M.; Mehar, V.; Merte, L. R.; Shipilin, M.; Lundgren, E.; Weaver, J. F.; Grönbeck, H.; Chem. Phys. Lett. 2018, 693, 84.

18. Reddy, D. H. K.; Yun, Y. S.; Coord. Chem. Rev. 2016, 315, 90.

19. Weng, X.; Cai, W.; Lan, R.; Sun, Q.; Chen, Z.; Environ. Pollut. 2018, 236, 562.

20. Springer, V.; Pecini, E.; Avena, M.; J. Environ. Chem. Eng. 2016, 4, 3882.

21. Albuquerque, A. S.; Ardisson, J. D.; Macedo, W. A. A.; López, J. L.; Paniago, R.; Persiano, A. I. C.; J. Magn. Magn. Mater. 2001, 226, 1379.

22. Jia, X.; Chen, D.; Jiao, X.; He, T.; Wang, H.; Jiang, W.; J. Phys. Chem. C 2008, 112, 911.

23. Albuquerque, A. S.; Ardisson, J. D.; Macedo, W. A. A.; J. Magn. Magn. Mater. 1999, 192, 277.

24. Choi, W. O.; Lee, J. G.; Kang, B. S.; Chae, K. P.; J. Magn. 2014, $151,38$.

25. IUPAC; Pure Appl. Chem. 1985, 57, 603.

26. Caetano, P. M. A.; Albuquerque, A. S.; Fernandez-Outon, L. E.; Macedo, W. A. A.; Ardisson, J. D.; J. Alloys Compd. 2018, $758,247$.

27. Kneller, E. F.; Luborsky, F. E.; J. Appl. Phys. 1963, 34, 656.

28. Coey, J. M. D.; Magnetism and Magnetic Materials, $1^{\text {st }}$ ed.; Cambridge University Press: Cambridge, 2010.

29. Dạbrowski, A.; Adv. Colloid Interface Sci. 2001, 93, 135.

30. Norte, T. H. O.; Marcelino, R. B. P.; Moreira, R. P. L.; Binatti, I.; Starling, M. C. V. M.; Amorim, C. C.; Pereira, E. S.; Rocha, W. R.; Lago, R. M.; J. Environ. Eng. (U. S.) 2018, 144, 04018001.

31. Anacona, J. R.; Figueroa, E. M.; J. Coord. Chem. 1999, 48, 181.
32. Anacona, J. R.; Rincones, M.; Spectrochim. Acta, Part A 2015 , $141,169$.

33. Resta, R.; Nature 2008, 453, 735.

34. Hameed, B. H.; Colloids Surf., A 2007, 307, 45.

35. Fakhri, A.; Adami, S.; J. Taiwan Inst. Chem. Eng. 2014, 45, 1001.

36. Martins, A. C.; Pezoti, O.; Cazetta, A. L.; Bedin, K. C.; Yamazaki, D. A. S.; Bandoch, G. F. G.; Asefa, T.; Visentainer, J. V.; Almeida, V. C.; Chem. Eng. J. 2015, 260, 291.

37. Kaur, S. P.; Rao, R.; Nanda, S.; Int. J. Pharm. Pharm. Sci. 2011, 3,30 .

38. Hou, J. P.; Poole, J. W.; J. Pharm. Sci. 1971, 43, 445003.

39. Babić, S.; Horvat, A. J. M.; Pavlović, D. M.; Kaštelan-Macan, M.; TrAC, Trends Anal. Chem. 2007, 26, 1043.

40. Orbeci, C.; Untea, I.; Nechifor, G.; Segneanu, A. E.; Craciun, M. E.; Sep. Purif. Technol. 2014, 122, 290.

41. Sellaoui, L.; Mechi, N.; Lima, É. C.; Dotto, G. L.; Lamine, A. B.; J. Phys. Chem. Solids 2017, 109, 117.

42. Ghaznavi, F.; Fatemi, S.; Joda, M.; Weber, W. J.; Morris, J. C.; Elovich, S. Y.; Zhabrova, G. M.; Freundlich, H. M. F.; Khan, A. R.; Ataullah, R.; AlHaddad, A.; Lagergren, S.; Langmuir, I.; Sips, R.; Toth, J.; J. Chem. Phys. 1971, 32, 311.

43. Ayawei, N.; Ebelegi, A. N.; Wankasi, D.; J. Chem. 2017, 3039817.

44. Dada, A. O.; Olalekan, A. P.; Olantunya, A. M.; Dada, O.; J. Appl. Chem. 2012, 3, 38.

45. Ho, Y. S.; McKay, G.; Process Biochem. 1999, 34, 451.

46. Azizian, S.; J. Colloid Interface Sci. 2004, 276, 47.

47. Khoe, G. H.; Robins, R. G.; J. Chem. Soc., Dalton Trans. 1988, 8,2015 .

48. Weng, L.; Van Riemsdijk, W. H.; Hiemstra, T.; J. Environ. Qual. 2012, 41, 628.

49. Kerkez-Kuyumcu, Ö.; Bayazit, Ş. S.; Salam, M. A.; J. Ind. Eng. Chem. 2016, 36, 198.

50. Kakavandi, B.; Esrafili, A.; Mohseni-Bandpi, A.; Jafari, A. J.; Kalantary, R. R.; Water Sci. Technol. 2014, 49, 147.

51. Pezoti, O.; Cazetta, A. L.; Bedin, K. C.; Souza, L. S.; Martins, A. C.; Silva, T. L.; Santos Jr., O. O.; Visentainer, J. V.; Almeida, V. C.; Chem. Eng. J. 2016, 288, 778.

52. Barrera, D.; Villarroel-Rocha, J.; Tara, J. C.; Basaldella, E. I.; Sapag, K.; Adsorption 2014, 20, 967.

53. Liu, H.; Hu, Z.; Liu, H.; Xie, H.; Lu, S.; Wang, Q.; Zhang, J.; RSC Adv. 2016, 6, 11454.

54. Li, Y.; Zhang, J.; Liu, H.; Water 2018, 10, 351.

55. Jalil, M. E. R.; Baschini, M.; Sapag, K.; Materials 2017, 10, 1345.

Submitted: February 27, 2020

Published online: June 19, 2020 